\title{
Educación asequible, accesible, aceptable y adaptable para los pueblos indígenas en México: Una revisión estadística
}

\author{
Available, accessible, acceptable and adaptable \\ education for indigenous people in Mexico: A \\ statistical review
}

Investigación

Anne Julia Köster

Universidad Europea Viadrina - Alemania Universidad Veracruzana - México aj.koester@hotmail.com

Recibido: 31 de marzo de 2016 / Aceptado: 16 de junio de 2016

\section{Resumen}

El artículo presenta una revisión estadística de la situación educativa de la población indígena en México. Debido a ello, se investiga si el subsistema de educación indígena cumple con los criterios 4-A definidos por el Comité de Derechos Económicos, Sociales y Culturales de las Naciones Unidas; el cual considera que la educación para los pueblos indígenas debe ser asequible, accesible, aceptable y adaptable. (1999, Comentario General núm. 13) El propósito de la revisión es describir el statu quo y visualizar los quehaceres de las instituciones y de los actores claves en el ámbito de la educación indígena, así como de la educación intercultural y bilingüe en México.

La revisión de las estadísticas del caso mexicano ha demostrado que los criterios 4-A no se cumplen. A la educación indígena le falta ser más asequible, porque el subsistema cuenta con mucho menos recursos por alumno en comparación con el sistema educativo general y con una infraestructura de un estándar más bajo. De igual manera, la educación indígena no es lo suficientemente accesible, ya que existen procesos, estructuras y mecanismos de discriminación, que resul- tan en la exclusión de pueblos originarios de procesos educativos. Asimismo, la educación indígena tampoco cuenta con un nivel de aceptabilidad, porque la falta de contextualización en la enseñanza hace que los alumnos indígenas perciban sus experiencias escolares como ajenas de sus realidades. Además, la educación indígena carece de una adaptabilidad, porque los programas educativos alternativos existentes no garantizan una atención a todas las necesidades de los diferentes grupos sociales indígenas.

Palabras clave: 4A-educación, pueblos indígenas, México, educación indígena, educación intercultural y bilingüe.

\footnotetext{
Abstract

The article presents a statistical review of the educational situation of the indigenous people in Mexico. For this reason, it is dissected if the subsystem of indigenous education meets the 4-A criteria. According to the United Nations' Committee for Educational, Social and Cultural Rights, indigenous education should be available, accessible, acceptable and adaptable. (1999,
}

Forma sugerida de citar: Köster, Anne (2016). Educación asequible, accesible, aceptable y adaptable para los pueblos indígenas en México: Una revisión estadística. Alteridad, 11(1), pp. 33-52. 
General Comment no. 13) The aim of the review is to describe the status quo and to visualize duties for institutions and key actors from the field of indigenous as well as intercultural and bilingual education in México.

The statistical review of the Mexican case showed that the criteria of a 4-A education for the indigenous Mexicans are not fulfilled. Indigenous education misses to be available due to the fact that the educational subsystem receives much less financial resources than the general educational system and counts with a lower standard of infrastructure. Furthermore, the indigenous education is no sufficiently accessible because there exist discriminative processes, structures and mechanisms that result in indigenous pupils being

\section{Introducción}

México se considera constitucionalmente un país pluricultural. (Art. 2) Esta realidad de diversidad cultural está fundamentada en sus pueblos originarios y se refleja, según el Instituto Nacional de Lenguas Indígenas (INALI), en un total de 364 variantes socio-lingüísticas (INALI, 2008, pp. 36-38). Estas variantes pertenecen a las 68 lenguas indígenas nacionales oficialmente reconocidas (Ley General de Derechos Lingüísticos, 2003, Art. 4).

Por ese motivo, México es el $6^{\circ}$ país lingüísticamente más diverso del mundo. (Lewis, 2009, tabla 1) De acuerdo al Instituto Nacional de Estadística y Geografía (INEGI), en 2010 se autoidentificaron 15.3 millones de mexicanos con 3 o más años de edad como indígenas; esta cifra representa un $14.9 \%$ de la población en México. De ellos, 6.9 millones hablan y 1.5 entienden una lengua indígena (INEGI, 2013, pp. 79-86).

Desde la creación de la Secretaría de Educación Pública (SEP) por José Vasconcelos en 1921, a lo largo de cinco etapas, se establecieron varias instituciones y se desarrollaron distintos modelos para garantizar la atención educativa de los pueblos originarios en México (DGEI / Sierra Soler, 2016, pp. 5-6).

1. En el periodo postrevolucionario del indigenismo entre 1921 y 1935, la SEP promovió la construcción de una nación unida, el excluded from participating at educational processes. Also, the indigenous education does not count with a preferable level of acceptability because the missing contextualization of the contents and the teaching makes the indigenous pupils perceive their experiences in school as far from their realities. Moreover, indigenous education lacks adaptability because the existing alternative educational programs do not guarantee an attendance of all the needs of the different social groups of the indigenous people.

Keywords: 4A-education, indigenous people, Mexico, indigenous education, intercultural and bilingual education.

mestizaje y la castellanización, para que los pueblos originarios formarán parte integral de la nación. El Departamento de Educación y Cultura Indígena creó varias casas de pueblo, que eran escuelas y a la vez centros comunitarios para los indígenas.

2. Luego, en la era del indigenismo institucionalizado, entre 1936 y 1969, el Departamento de Educación y Cultura Indígena fue absorbido en el Departamento Autónomo de Asuntos Indígenas, y además se creó el Instituto Nacional Indigenista para promover un desarrollo integral regional en las comunidades originarias.

3. En la tercera etapa, a partir de 1970, la SEP desarrolló el modelo bilingüe y bicultural, que opta desde entonces a alfabetizar a los alumnos indígenas por promotores culturales y maestros bilingües en sus lenguas originarias, en vez de solo castellanizarlos. Como sucesor de la Dirección Extraescolar del Medio Indígena, se creó en 1978 la Dirección General de Educación Indígena (DGEI), que forma parte hasta hoy en día de la Subsecretaría de Educación Básica de la SEP. La DGEI construyó y continúa manteniendo un sistema educativo paralelo con escuelas públicas del nivel educativo inicial, preescolar y primaria en las comunidades originarias en 24 de las 32 entidades federativas del país. 
4. Con la ratificación del Convenio 169 sobre pueblos indígenas y tribales de la Organización Internacional de Trabajo (OIT) en 1990 y con el reconocimiento constitucional de la nación mexicana como pluricultural en 1992, se empezó el periodo del empoderamiento de los pueblos originarios mexicanos. El levantamiento del Ejercito Zapatista de Liberación Nacional (EZLN) a partir de 1994, resultó en los Acuerdos de San Andrés dos años después, los cuales formaban la base para el reconocimiento legal de sus derechos a una educación culturalmente y lingüísticamente pertinente, para la adaptación de la legislación nacional a los acuerdos internacionales, tales como la declaración de los derechos humanos (UDHR, 1948), el convenio internacional sobre derechos económicos, sociales y culturales (ICESCR, 1976) y la declaración de los derechos de los pueblos indígenas (UNDRIP, 2007), entre otros, así como la creación de la Coordinación General de Educación Intercultural y Bilingüe (CGEIB) en 2001. Esta sub-institución de la SEP introdujo el modelo de la educación intercultural y bilingüe y pretendía la interculturalización transversal de los sistemas educativos y sus actores en las 32 entidades federativas (al nivel macro), sus supervisiones escolares (al nivel medio) y sus instituciones educativas públicas, incluso las escuelas indígenas (al nivel micro). La interculturalización tiende a construir el conocimiento y el aprendizaje a base de la cosmovisión de la propia comunidad en vez de por un solo currículo nacional homogeneizante y basado en una cosmovisión occidental. Así busca apoyar a los pueblos originarios a preservar su propia cultura y lengua a lo largo de su trayectoria educativa, así como a sensibilizar a todos los actores en el ámbito educativo sobre la diversidad cultural y lingüística existente en México, para que la conozcan, consideren, valoren y aprecien (CGEIB, 2015, 2014, pp. 8-9).
- La quinta etapa inició con la Reforma Integral de la Educación Básica en 2011, la cual se define en el Acuerdo 592, en donde por primera vez se estableció, como parte del tercer campo de formación 'Exploración y comprensión del mundo natural y social, una de cuatro asignaturas estatales elegibles, llamada 'Lengua y cultura indígena', a través de la cual se permite a las escuelas del sistema educativo general en el primer grado de la secundaria, impartir contenidos contextualizados, diversificados y en lengua indígena, cuando haya al menos un $30 \%$ de alumnos indígenas en el aula. (pp. 29, 31) De igual manera, en el marco del Plan Nacional de Desarrollo 2013-2018, se modificó el tercer artículo constitucional, estableciendo la educación con calidad como un derecho; y se realizó la Reforma Educativa en 2013, la cual está articulada en el Programa Sectorial de Educación 2013-2018 de la SEP. Uno de los objetivos es asegurar una mayor cobertura, inclusión y equidad educativa entre todos los grupos de la población, como los pueblos originarios, para la construcción de una sociedad más justa. Específicamente, la cuarta de las siete estrategias se dirige a la atención a la diversidad, promoviendo a impulsar la educación intercultural en todos los niveles educativos y a reforzar la educación intercultural y bilingüe para las poblaciones que hablen lenguas originarias. (pp. 54-59) Además, se aprobó el Programa Especial de la Educación Intercultural 20142018 (PEEI) de la CGEIB y el Programa para la inclusión y equidad educativa para el ejercicio fiscal 2016 (PIEE) de la SEP, el cual propone una educación para los pueblos originarios basada en un modelo educativo de atención a la diversidad con inclusión y equidad.

Desde la reforma educativa en 2013, la garantía del acceso de todos los mexicanos a una educación con calidad, establecida en el artículo tercero constitucional, es el Instituto Nacional 
para la Evaluación de la Educación (INEE) quien tiene el papel de evaluar y supervisar el proceso de desarrollo educativo en términos de calidad y equidad. Sus indicadores de evaluación se basan en esta normativa nacional y además en un enfoque de derechos, reconociendo el derecho universal a la educación, que se encuentra en la declaración de los derechos humanos (Art. 26), así como en el convenio internacional sobre derechos económicos, sociales y culturales (Art. 13, 14) y también reconociendo a las personas como "titulares de derechos que deben estar en posibilidad de hacer uso de diversos mecanismos para exigirlos y como titulares de obligaciones a las autoridades responsables de garantizar su cumplimento" (INEE, 2016, p. 14).

El INEE retoma, contextualiza y aplica la propuesta realizada por Tomasevski, del Comité de Derechos Económicos, Sociales y Culturales (CESCR) de la Organización de las Naciones Unidas (ONU), para evaluar la calidad y equidad de la educación en México. El enfoque indica que una educación con calidad y equidad es compuesta por los criterios 4 -A, por lo que se considera que es asequible, accesible, aceptable y adaptable para todos (1999, Comentario General núm. 13).

En el presente trabajo se revisaron estadísticas para evaluar si la educación de la población indígena en México corresponde a estos criterios definidos por Tomasevski y contextualizados por el INEE. El propósito de esta investigación es entender la situación educativa actual de los pueblos originarios en México y visualizar los retos y quehaceres de las instituciones y actores claves en el ámbito de la educación indígena, así como de la educación intercultural y bilingüe.

Trabajos enfocados en el tema incluyen artículos sobre la historia y el estatus actual de la educación indígena e intercultural en México (Martínez Buenabad, 2011, Bertely Busquets, 2002, Dietz y Mateos Cortés, 2011), así como estudios sobre la calidad de la educación indígena en México (Tapia Uribe, 2003, Schmelkes et al., 2011, INEE, 2016) y un análisis de los problemas de medición de la situación educativa de los pueblos indígenas mexicanos (Schmelkes, 2013).

Como fuentes de información sobre las políticas educativas indígenas, interculturales y bilingües en México, se deben considerar las publicaciones de la Dirección General de Educación Indígena (DGEI) y de la Coordinación General de Educación Intercultural y Bilingüe (CGEIB); por ejemplo, la reforma integral de la educación básica indígena para la atención educativa de calidad a la diversidad lingüística y cultural (SEP/DGEI, 2009a) y el Programa Especial de Educación Intercultural 2014-2018 (CGEIB, 2014).

Además, la consulta al Plan de diez años para desarrollar el Sistema Educativo Nacional, elaborado por Narro Robles y Moctezuma Navarro (2012), ayuda a entender mejor los retos de la población indígena y los deberes políticos con respeto a la mejora de su educación.

\section{Fundamentación teórica}

El marco teórico de este trabajo se apoya en cuatro distinciones analíticas desarrolladas por Tomasevski y que son los criterios 4-A de una educación con calidad y equidad: estos son asequibilidad, accesibilidad, aceptabilidad y adaptabilidad (1999, Comentario General núm. 13), y a continuación se explican.

1. Educación asequible:

Con asequibilidad se refiere a que habrá suficientes instituciones y programas educativos disponibles que funcionen dentro de una jurisdicción. Esto incluye una infraestructura como edificios, instalaciones sanitarias, agua potable, materiales didácticos y en algunos casos también bibliotecas, computadoras y tecnología informática. Además, significa que los docentes deberían estar bien formados y recibir un salario adecuado a su contexto. Los padres de familia deberían tener la libertad de elegir la educación para sus hijos de acuerdo al principio del interés superior del menor. 
2. Educación accesible:

Accesibilidad implica que dentro de una jurisdicción todos tengan la posibilidad de participar en procesos educativos sin ser discriminados o excluidos. La accesibilidad se refiere a 3 dimensiones interrelacionadas, la dimensión de la no-discriminación, la accesibilidad física y la accesibilidad económica. Esto significa que la educación debería ser legalmente y de facto accesible para todos, incluso para los grupos más vulnerables, por tanto, la exclusión de la educación por origen étnico o contextual, color de piel, sexo, idioma, religión, opinión, estatuto socio-económico, nacimiento o discapacidad debería ser eliminada. Asimismo, la oferta educativa debería ser accesible en un terreno seguro y geográficamente razonable, o bien, por vías de la tecnología moderna. También, la educación debería ser obligatoria y gratuita para todos.

3. Educación aceptable:

Con aceptabilidad se refiere a que la forma y el contenido de la educación, incluso el currículo y los métodos de enseñanza, deberían ser contextualizados, diversificados y adecuados para los alumnos y también para los padres de familia. Esto significa que la educación debería ser relevante, culturalmente apropiada y de buena calidad, para que los alumnos se sientan seguros, respetados y acogidos en las escuelas. Deberían creer que ahí adquieren conocimientos que coinciden con sus intereses y que estos les resultan útiles para su vida actual y futura. Por tanto, la educación debería ser impartida y regularmente evaluada de acuerdo a las dimensiones de calidad elaboradas desde la perspectiva de los alumnos y legalmente reconocidas por el Estado.

4. Educación adaptable:

Adaptabilidad implica que la educación debería ser compatible con los requerimientos, intereses y condiciones específicas de todos los niños en las sociedades y comunidades de contextos sociales y cul- turales diversos y transformativos, específicamente de niños con discapacidades o de grupos minoritarios como los indígenas. Así, la educación adaptable incluye además el diseño de una oferta educativa para niños excluidos de la educación formal, por ejemplo, refugiados o niños internamente desplazados, padres jóvenes, encarcelados o trabajadores; de esta manera, a través de la educación, todos los derechos humanos deberían ser fortalecidos.

El INEE constata que la asequibilidad y la accesibilidad se refieren al derecho $a$ la educación, y que la aceptabilidad y la adaptabilidad corresponden al derecho en la educación. Esta distinción supone que, por un lado, los mexicanos tienen derecho a acceder a la escuela, y, por otro, que la escuela garantiza la oferta de condiciones materiales, socioafectivas y pedagógicas requeridas, para que todos puedan participar en procesos educativos.

Entonces, para que todos los mexicanos tengan el derecho a una educación de calidad y equitativa, deben tener garantizados por lo menos tres derechos:

1. El derecho de acceso a la educación, el cual se refiere a que todos tengan posibilidades reales de disponer de una oferta educativa de calidad.

2. El derecho de permanencia en la escuela, que significa que todos puedan desarrollar una trayectoria escolar sin rezago, así como que puedan egresar de la escuela oportunamente acorde con la edad típica de terminación de la educación obligatoria, en condiciones flexibles y correspondientes a sus necesidades en contextos culturales y sociales diversos.

3. El derecho de logro de aprendizaje, que implica que todos reciban una educación pertinente, aceptable y culturalmente adecuada y que a la vez sea relevante, útil y significativa para sus vidas.

Además, para cumplir con sus obligaciones, el Estado Mexicano tiene el deber de promover, respetar, proteger y garantizar que se cumplan estos tres derechos (INEE, 2016, pp. 14, 15). 


\section{Fundamentación metodológica}

En base al modelo de Tomasevski (2004, pp. 352, $353,388)$, se desarrollaron diez indicadores que ayudan a medir la calidad y equidad educativa. Estos indicadores fueron adaptados al contexto mexicano multiétnico, específicamente al objetivo del presente trabajo, el cual es revisar la situación educativa de los indígenas mexicanos; para medir el cumplimento, por una parte, de sus derechos a una educación de calidad y equidad y, por otra, las obligaciones del Estado para garantizarles dichos derechos.

Para ejecutar el análisis de acuerdo a los diez indicadores presentados a continuación, se revisaron estadísticas publicadas por diferentes instituciones gubernamentales, como el INEGI, la SEP, el INEE, entre otras.

Tabla 1. Obligaciones gubernamentales, marcos de las actividades del gobierno e indicadores para medir la garantía de una educación de acuerdo a los 4 As para pueblos originarios en México

\begin{tabular}{|c|c|c|c|}
\hline Criterios 4-A & $\begin{array}{l}\text { Obligaciones } \\
\text { gubernamentales }\end{array}$ & $\begin{array}{l}\text { Marco de actividad } \\
\text { del Gobierno }\end{array}$ & Indicadores \\
\hline Asequibilidad & $\begin{array}{l}\text { Garantizar } \\
\text { 1. infraestructura: edificios y } \\
\text { materiales didácticos; } \\
\text { 2. capital humano: docentes } \\
\text { calificados y adecuadamente } \\
\text { pagados; } \\
\text { 3. libertad de padres a elegir } \\
\text { educación de acuerdo al } \\
\text { interés del niño. }\end{array}$ & $\begin{array}{l}\text { 1. nivel entre asignaciones } \\
\text { presupuestarias y obligacio- } \\
\text { nes legales con respeto a la } \\
\text { infraestructura; } \\
\text { 2. nivel de formación y pago del } \\
\text { personal docente; } \\
\text { 3. cobertura de oferta edu- } \\
\text { cativa variada para todos los } \\
\text { derechohabientes; }\end{array}$ & $\begin{array}{l}\text { Por cada subsistema y grupo } \\
\text { social: } \\
\text { 1. porcentaje del presupuesto } \\
\text { nacional para la educación; } \\
\text { 2. promedio de títulos académi- } \\
\text { cos y de pago; } \\
\text { 3. índice de cobertura de oferta } \\
\text { educativa variada; }\end{array}$ \\
\hline Accesibilidad & $\begin{array}{l}\text { Garantizar la } \\
\text { 4. posibilidad de participar } \\
\text { en procesos educativos } \\
\text { sin ser discriminados o } \\
\text { excluidos; } \\
\text { 5. accesibilidad física: segu- } \\
\text { ridad y ubicación; } \\
\text { 6. accesibilidad económi- } \\
\text { ca: educación obligatoria y } \\
\text { gratuita; }\end{array}$ & $\begin{array}{l}\text { 4. políticas y medidas prácticas } \\
\text { para erradicar la discrimina- } \\
\text { ción y exclusión en el ámbito } \\
\text { educativo; } \\
\text { 5. cobertura de educación en } \\
\text { todas partes del país; } \\
\text { 6. nivel de participación educa- } \\
\text { tiva de acuerdo al nivel socio- } \\
\text { económico del derechohabiente; }\end{array}$ & $\begin{array}{l}\text { Por cada subsistema y grupo } \\
\text { social: } \\
\text { 4. índices de discriminación y } \\
\text { exclusión educativa } \\
\text { 5. índice de cobertura por ubica- } \\
\text { ción geográfica; } \\
\text { 6. porcentaje de abandono esco- } \\
\text { lar por falta de recursos; }\end{array}$ \\
\hline Aceptabilidad & $\begin{array}{l}\text { Garantizar } \\
\text { 7. impartición de contenidos } \\
\text { relevantes, contextualizados } \\
\text { y diversificados; } \\
\text { 8. evaluación de la educa- } \\
\text { ción de acuerdo a dimensio- } \\
\text { nes de calidad; }\end{array}$ & $\begin{array}{l}\text { 7. planeación curricular, nivel } \\
\text { de flexibilización para impartir } \\
\text { contenidos y aplicar métodos de } \\
\text { enseñanza; } \\
\text { 8. mecanismos de evaluación y } \\
\text { de elaboración de dimensiones } \\
\text { de calidad; }\end{array}$ & $\begin{array}{l}\text { Por cada subsistema y grupo } \\
\text { social: } \\
\text { 7. grado de relevancia, contex- } \\
\text { tualización y diversificación de } \\
\text { los contenidos y métodos; } \\
\text { 8. existencia de un sistema de } \\
\text { evaluación; }\end{array}$ \\
\hline Adaptabilidad & $\begin{array}{l}\text { Garantizar } \\
\text { 9. flexibilidad y compatibili- } \\
\text { dad de la oferta educativa } \\
\text { con intereses, requerimien- } \\
\text { tos y condiciones de los } \\
\text { derechohabientes; } \\
\text { 10. oferta educativa para } \\
\text { derechohabientes excluidos } \\
\text { de la educación formal. }\end{array}$ & $\begin{array}{l}\text { 9. planeación y programación de } \\
\text { una oferta educativa para cual- } \\
\text { quier grupo social de acuerdo a } \\
\text { sus intereses, requerimientos y } \\
\text { condiciones; } \\
\text { 10. cobertura de oferta educativa } \\
\text { para todos los derechohabien- } \\
\text { tes excluidos de la educación } \\
\text { formal. }\end{array}$ & $\begin{array}{l}\text { Por cada subsistema y grupo } \\
\text { social: } \\
\text { 9. existencia de programas } \\
\text { educativos para cualquier grupo } \\
\text { social; } \\
\text { 10. porcentaje de derechoha- } \\
\text { bientes excluidos de la educa- } \\
\text { ción formal y no cubiertos por } \\
\text { una oferta alternativa. }\end{array}$ \\
\hline
\end{tabular}

Basado en los indicadores de Tomasevski (2004, pp. 352, 353, 388), adaptado al contexto mexicano y elaborado por la autora. 


\section{Revisión estadística y recomendaciones}

En México, los pueblos originarios tienen acceso a la educación general o indígena; el sub-sistema educativo indígena o bilingüe y bicultural, ofrece educación a los niños y niñas indígenas en sus comunidades monolingües y bilingües y se compone de la educación inicial, preescolar y primaria indígena (SEP, 2001, pp. 6, 8, 10; 2009, p. 5).

La siguiente gráfica demuestra las fichas básicas del subsistema de la educación indígena en México en el ciclo escolar 2014-2015.

Gráfico 1. Cifras del subsistema de la educación indígena en México. Centros educativos, matrícula y docentes de la educación inicial, preescolar y primaria indígena. (DGEI / Sierra Soler, 2016, p. 2)

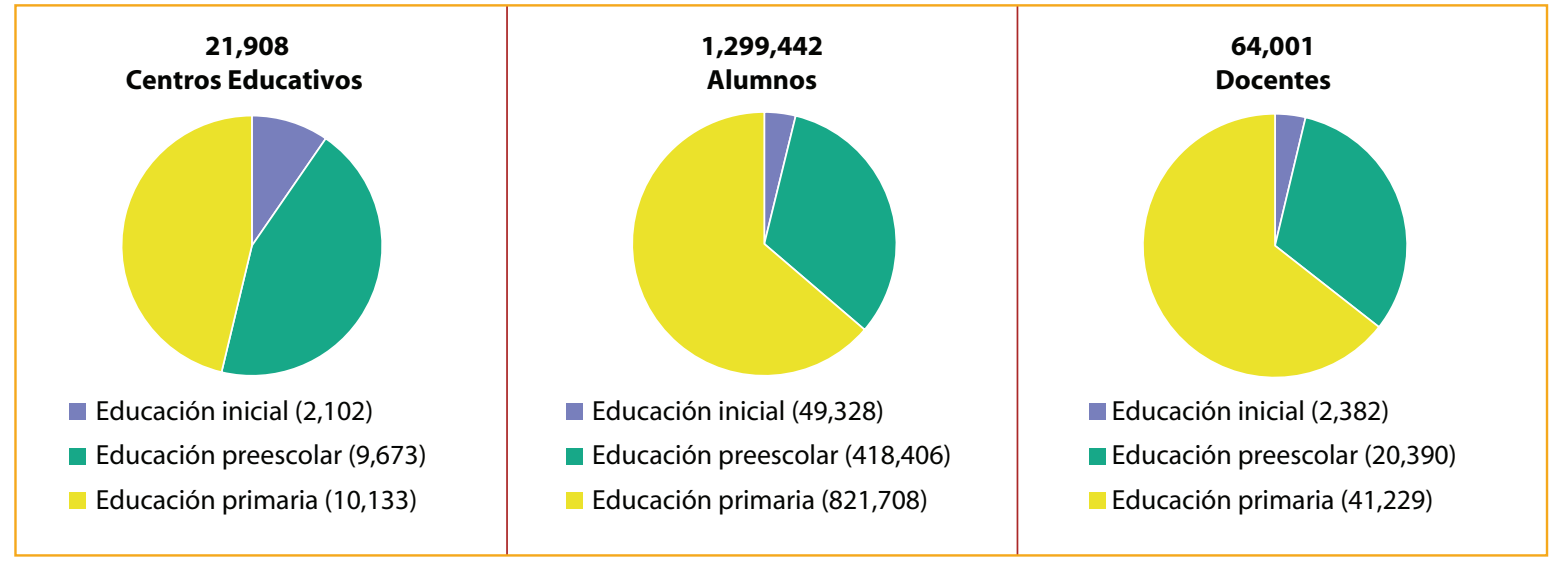

Para poder entender la situación educati- número de alumnos inscritos en el sistema educativa de los pueblos originarios en México, se debe vo general e indígena. también tener un panorama comparativo entre el

Gráfico 2. Cifras del subsistema de la educación indígena en México. Centros educativos, matrícula y docentes de la educación inicial, preescolar y primaria indígena. (DGEI / Sierra Soler, 2016, p. 2)

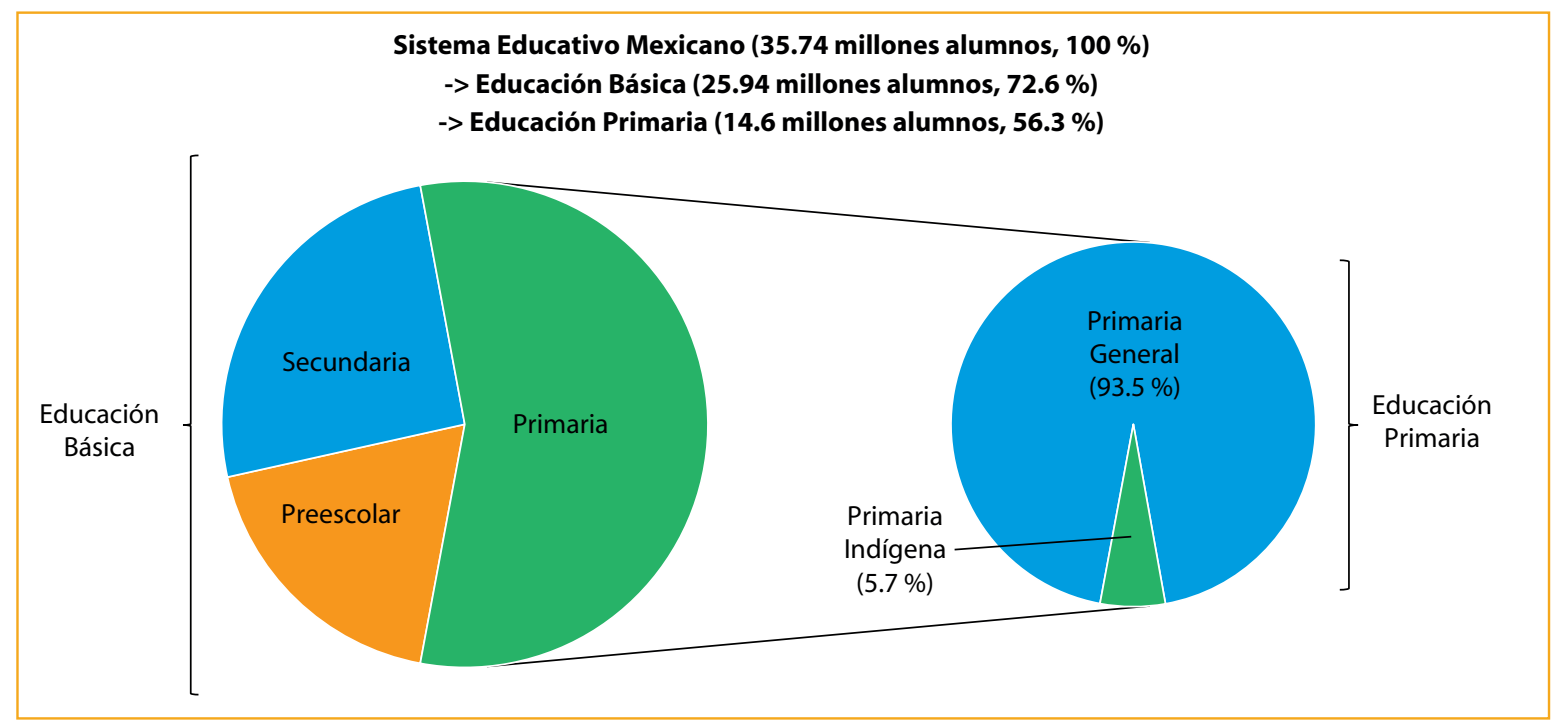


En el ciclo escolar 2013-2014 se matricularon un total de 35.74 millones de alumnos en el sistema educativo nacional. Entre ellos, había 14.6 millones de alumnos inscritos en la educación primaria, de los cuales 13.6 millones (o un $93.5 \%$ de alumnos de primarias) pertenecían al sistema educativo general; éstos fueron atendidos por 524450 maestros en 637872 grupos y en 77821 escuelas primarias. Los otros 834572 alumnos de primarias (que corresponden a un 5.7\%) pertenecían a la educación primaria indígena o bilingüe y bicultural y fueron atendidos por 36246 maestros en 65268 grupos, en 10102 escuelas indígenas y en 24 de 32 entidades federativas. (SEP, 2014, pp. 15, 16, 61, 76, 77).

Actualmente, los pueblos originarios mexicanos cuentan con la participación educativa, eficiencia terminal y cuota de aprobación más baja del país. (Narro Robles y Moctezuma Navarro, 2012, pp. 170, 171) Por consiguiente, se demuestra que su rezago educativo y la desigualdad que enfrentan, tienen que ver con una oferta insuficiente para una educación de calidad y equidad de acuerdo a los criterios 4-A.

\section{La asequibilidad de la educación para los pueblos indígenas en México}

\section{Indicador: Porcentaje del presupuesto nacional para la educación general e indígena}

Para entender el desequilibrio entre los recursos para los alumnos del sistema educativo general e indígena, se deben comparar los presupuestos designados a cada uno de ellos. En 2012, México invirtió el 5.2\% de su PIB en educación. El porcentaje del presupuesto nacional para la educación fue de $19.6 \%$ y equivalió a 564980 millones de pesos mexicanos.

En comparación con los otros niveles educativos (medio superior y superior), la educación básica gastó un $60 \%$ del presupuesto, mientras que el Fondo de Aportaciones para la Educación Básica recibió 293965 millones de pesos mexicanos. Por tanto, se pagaron por alumno en toda la Educación Básica un promedio de 11300 pesos mexicanos, en el nivel de primaria del sistema educativo general era un promedio de 14200 pesos mexicanos.

La Dirección General de Educación Indígena (DGEI), quien es la responsable para financiar la educación indígena en México, recibió 388 millones pesos mexicanos en 2012, equivalentes a $0.06 \%$ del presupuesto anual y que resultó en una inversión de aproximadamente 300 pesos mexicanos por alumno.

Estas cifras demuestran que el gobierno mexicano invirtió en el año 2012 casi 38 veces más en la educación básica que en la educación indígena. (OCDE, 2015, p. 3, Mejía Botero, 2012, p. 22, Serdán Rosales, 2011, pp. 14, 16, 19, INEE, 2012, p. 2, Narro Robles y Moctezuma Navarro, 2012, p. 172).

Ese desequilibrio de presupuesto entre la educación general e indígena fortalece el rezago educativo de los indígenas. Por la falta de recursos, el Estado no puede cumplir con sus obligaciones jurídicas de ofrecer una educación indígena de calidad y equidad a los pueblos originarios, y por consecuencia, las escuelas indígenas tienen el peor nivel de infraestructura y organización escolar en México.

9 de cada 10 escuelas preescolares y 4 de cada 5 escuelas primarias de la modalidad indígena carecen de personal directivo; además, en 2 de cada 5 de estas escuelas hacen falta mesas y sillas para los docentes. Más aún, en 7 de cada 10 preescolares y en 3 de cada 5 primarias indígenas, un docente atiende a grupos de más de un grado (INEE, 2015, p. 70).

En 2007, un 60\% de los alumnos indígenas estaban inscritos en escuelas con condiciones de infraestructura precarias y solo el $10 \%$ de los alumnos en escuelas indígenas tenía acceso a materiales didácticos y a infraestructura adecuada, como a libros de texto y bibliotecas. Para 2006, el $4.1 \%$ de las escuelas primarias indígenas tuvieron equipamiento de computadoras, sin embargo, el promedio en las escuelas primarias generales era del 28.8\% (Schmelkes et al., 2011, p. 3). 
Gráfico 3. Presupuesto Nacional de México para la educación en 2012. (OCDE, 2015,Mejia Botero, 2012, Serdán Rosales, 2011, DGEl / Sierra Soler, 2016, p.21

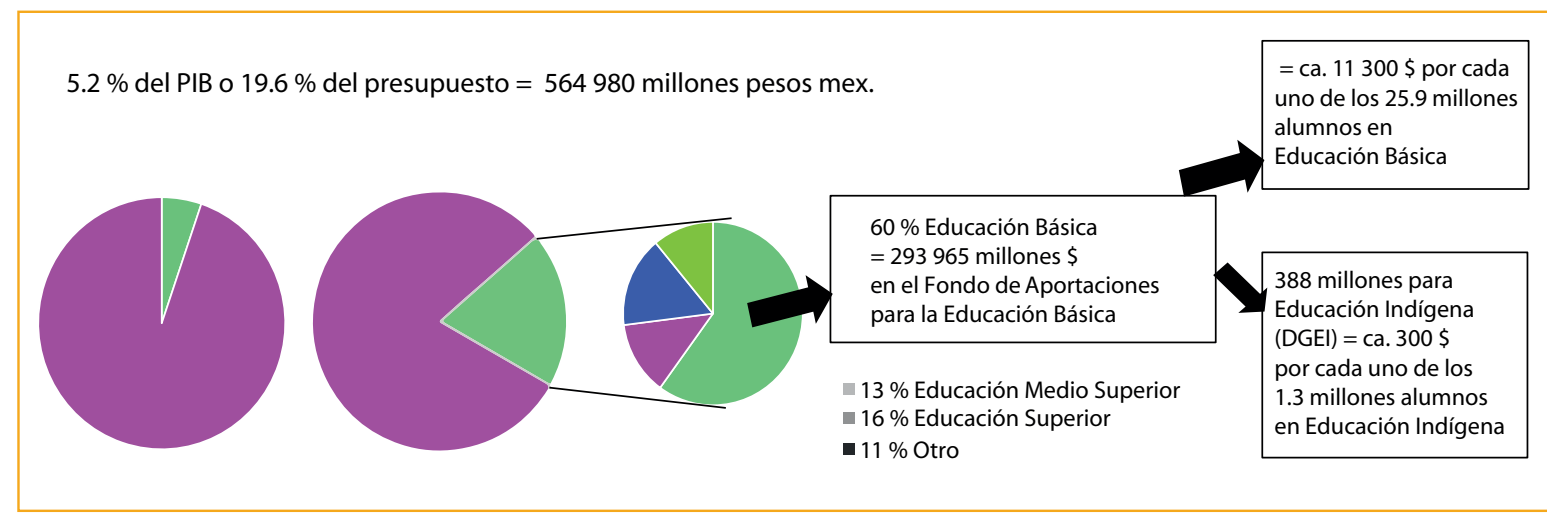

Recomendación: Redistribuir el presupuesto anual para la educación de una manera más igualitaria entre el sistema general e indígena, para que los alumnos del sistema indígena puedan aprender bajo condiciones más favorables. Disponer de recursos para un programa especial de mejora de infraestructura educativa para los pueblos originarios favorecería a su acceso equitativo a la educación.

Además, el presupuesto anual para la educación indígena depende de las coyunturas políticas y debido a ello, la cantidad de los recursos disponibles varía cada año. En ese orden de ideas, los actores en las instituciones del sistema educativo indígena no son capaces de poder planificar actividades a mediano o largo plazo. Por ejemplo, en 2012, la Dirección General de Educación Indígena (DGEI) recibió 30\% menos que el presupuesto del año anterior (388 millones en 2012 y 536 millones en 2011) (Márquez Jiménez, 2012, p. 112, Serdán Rosales, 2011, p. 19).

Recomendación: Determinar un presupuesto anual para la DGEI y las demás instituciones del ámbito educativo por todo el sexenio, esto para garantizar que tengan más seguridad en su planeación de proyectos y para que puedan realizar intervenciones en un largo plazo.

\section{Indicador: Promedio de títulos académicos y de pago de los docentes}

Para que el personal docente pueda enseñar a los alumnos indígenas con calidad y motivación, se requiere una formación docente adecuada y de calidad, así como un ingreso equitativo. Los docentes del sistema educativo indígena cuentan, en promedio, con menos títulos académicos que los maestros del sistema educativo general. En el ciclo escolar 2007-2008, un 15\% de los maestros del nivel preescolar indígena y un $13 \%$ de los maestros de escuelas primarias indígenas contaban con un título de licenciatura, por el contrario, la mitad del personal docente en el nivel preescolar y primaria del sistema educativo general terminó una licenciatura (51.6\% y $50.7 \%)$. Estas cifras mejoraron en los últimos años, como se muestra en la gráfica siguiente (INEE, 2015, p. 40, DGEI / Sierra Soler, 2016, p. 20).

Recomendación: Establecer que un título de licenciatura sea el requisito mínimo para poder estar empleado como docente en el sistema educativo indígena y ofrecer un programa de profesionalización obligatorio para que todos docentes activos obtengan un título en el marco de su formación continua. 
Además, en México los ingresos de los docentes difieren de acuerdo al sistema educativo en el que están empleados. El salario mínimo mensual de los docentes indígenas es en promedio más bajo comparado con sus colegas empleados en el sistema educativo general. Por ejemplo, en el ciclo escolar 20112012 , los docentes en escuelas primarias indígenas de 20 a 24 años, recibieron en promedio un salario mensual de 9000 pesos mexicanos, mientras que un docente en una escuela primaria general ganó 2500 pesos más, lo cual corresponde a una brecha salarial del 21\% (INEE, 2015, pp. 69, 70).

Recomendación: Nivelar el salario para que todos los docentes, da igual, en cual sistema educativo estén empleados, reciban el mismo pago para la misma cantidad de horas de trabajo.

Gráfico 4. Perfil profesional de los docentes del sistema de la educación indígena en la región sur sur-este de México. (OGEl/Sierra Soler, 2016, p. 20)

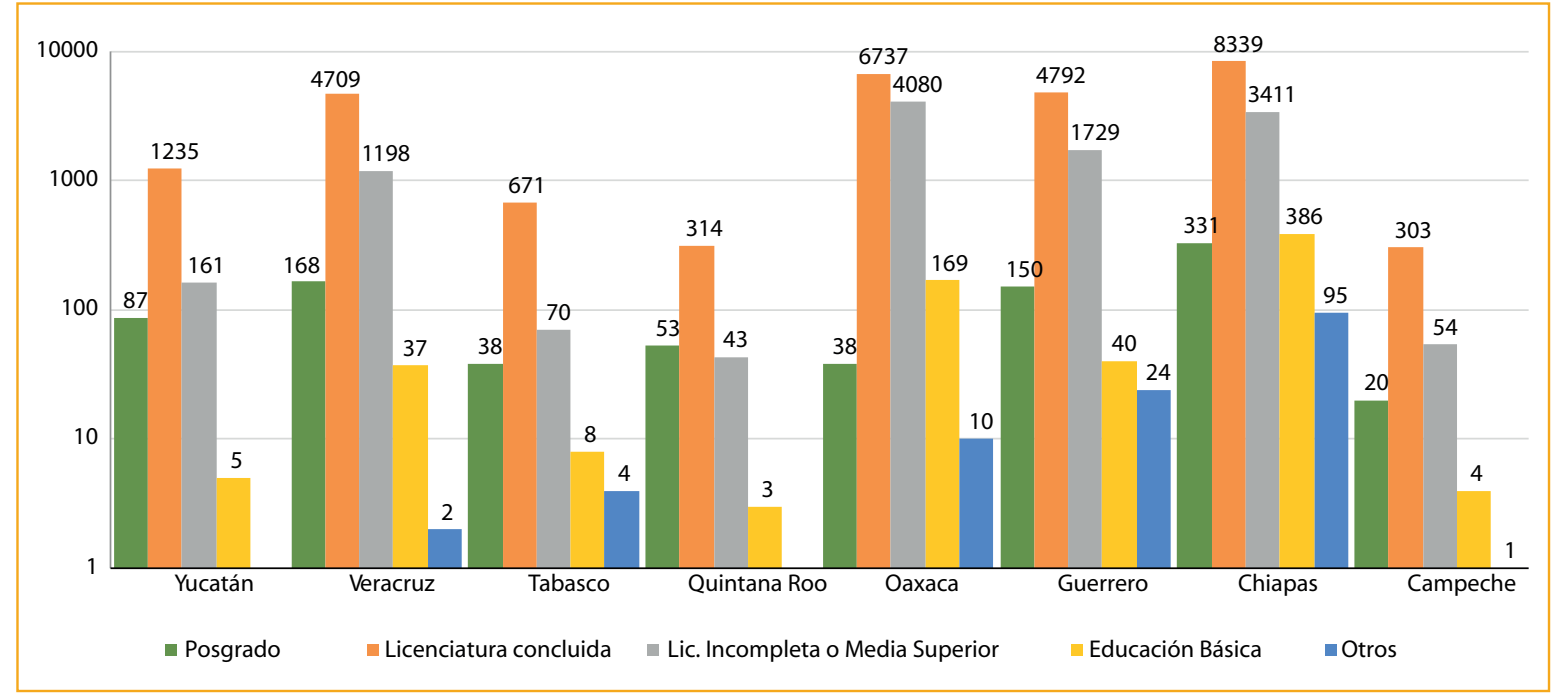

Indicador: Índice de cobertura de oferta educativa variada

Existe un sistema educativo indígena en 24 de las 32 entidades federativas, en donde hay originariamente un porcentaje de población indígena elevado. En sus comunidades, los indígenas pueden recibir una educación en su lengua desde el nivel inicial hasta primaria. Pero este sistema no toma en cuenta que los pueblos originarios son el grupo social en México que más migra. Cuando salen de sus comunidades, ya no tienen acceso a una educación en su lengua y de acuerdo a su contexto cultural. En estos casos los padres de familia están limitados a elegir una oferta educativa cultural- y lingüísticamente adecuada y pertinente (DGEI, 2009, p. 2).
Recomendación: Establecer centros de aprendizaje de lenguas indígenas gratuitos, en los lugares a donde más migran los pueblos originarios, para así garantizar la disponibilidad de una oferta educativa en sus lenguas aunque ya no se encuentren en sus comunidades originarias.

\section{La accesibilidad de la educación para los pueblos indígenas en México}

\section{Indicador: Indices de discriminación y exclusión educativa}

Según la constitución, todos los mexicanos tienen las mismas oportunidades de acceso al sistema educativo nacional (Art. 2) pero, a pesar de esta 
base legal, existen obstáculos para que los indígenas tengan un acceso equitativo.

Según el Consejo Nacional para Prevenir la Discriminación (CONAPRED) (2013) existen procesos, estructuras y mecanismos de discriminación que excluyen a pueblos originarios mexicanos de los procesos educativos. En la encuesta Nacional sobre Discriminación en México en 2010, señaló que un $24 \%$ de los hablantes de una lengua indígena no se les respetan sus derechos por su acento al hablar o por su forma de vestir, y a un $37 \%$ no se les reconocen sus derechos ante los demás. En relación con el derecho de los pueblos originarios a la educación, se nota su discriminación y exclusión cuando se analiza su tasa de analfabetismo. En 2010, el 28.2\% de la población de 15 años o más, hablante de una lengua indígena, no sabía leer y escribir. En el caso de las mujeres se agrava, porque contaron con una tasa de analfabetismo del $33.8 \%$, cuando un $22.3 \%$ de los hombres no podían leer ni escribir. En comparación, el promedio nacional de analfabetas era del 6.9\%, la tasa del analfabetismo de las mujeres ascendió a un $8.1 \%$ y el de los hombres a un 5.6\% (INEGI, 2013, p. 93, 137).

Recomendación: Por un lado, diseñar programas especiales para la alfabetización de los pueblos originarios de acuerdo a su contexto cultural y lingüístico, y por otro, promover la nodiscriminación con medidas educativas informales, como campañas o contenidos en los medios de comunicación, al igual que con medidas educativas formales, como proyectos escolares o el uso de materiales didácticos que aborden el tema.

\section{Indicador: Indice de cobertura \\ de oferta educativa por ubicación geográfica}

Como se puede ver en la gráfica, existe una relación directa entre la cantidad de personas que viven en un lugar y el porcentaje de asistencia escolar.

Gráfico 5. Porcentaje de la población mexicana que asiste en la escuela, 2010. (INEGl, 2013, p. 146)

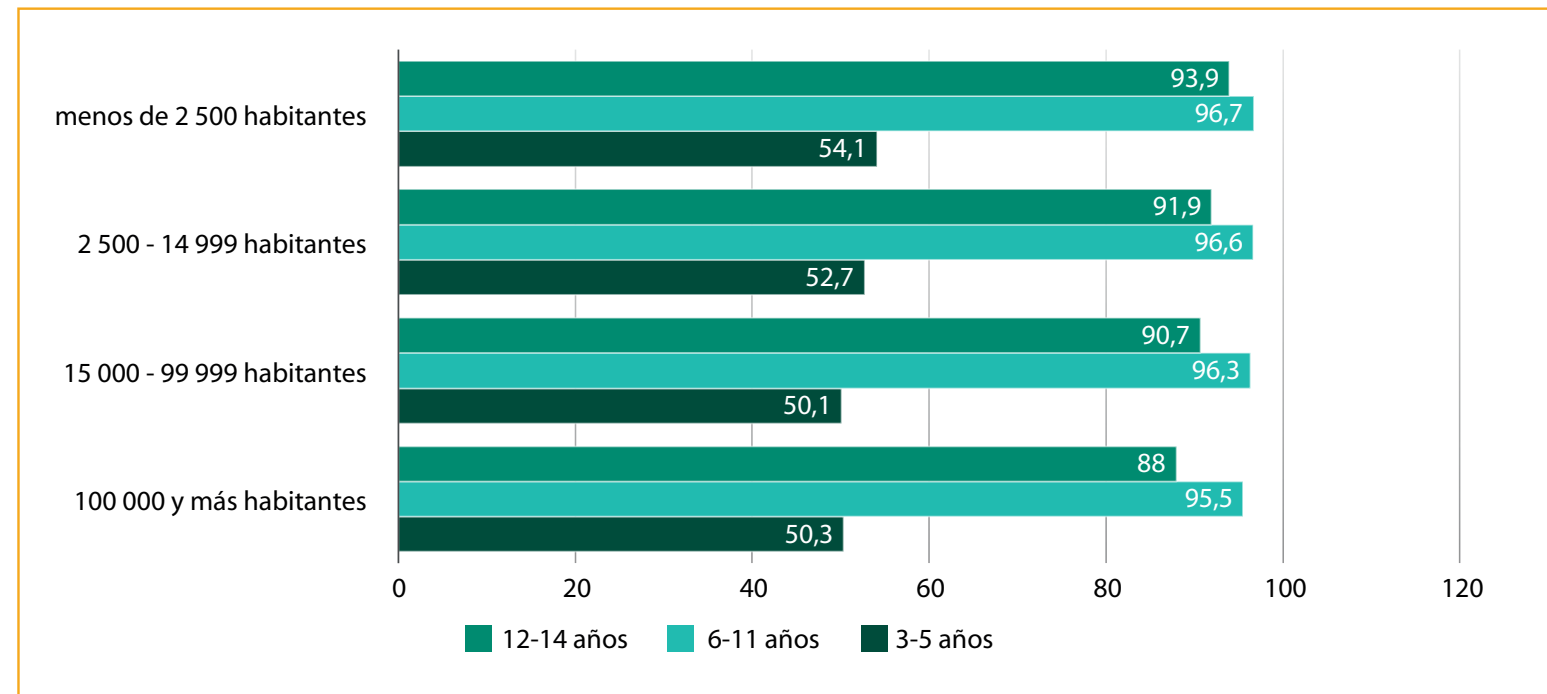

Conforme crece el tamaño de la localidad, aumenta la cobertura del sistema educativo. La diferencia porcentual más elevada entre las localidades con más y menos habitantes corresponde a los jóvenes mexicanos entre 12 y 14 años, con casi $6 \%$.
En tanto, la población indígena se presenta el escenario siguiente. Debido a que solo el 9.9\% de los hablantes de una lengua indígena de 5 años o más vivía en 2010 en localidades con más que 30 000 habitantes, la mayoría tenía y todavía mantiene sus hogares en zonas rurales, cuentan con una 
cobertura de oferta educativa menor que los no indígenas (Cervera, 2015, p. 25).

De acuerdo a Schmelkes (2013, p. 7), se reproduce la desigualdad con los más pequeños de origen indígena. A pesar de que la Ley General de Educación obliga a la población de 5 años de edad a cursar un año de preescolar, la oferta de educación preescolar en comunidades indígenas es menos completa que en otras partes del país, por lo que un $76 \%$ de los niños originarios solo asisten a una educación preescolar, en contraste con el $90 \%$ de los niños no indígenas que asisten a ella.

Recomendación: Impulsar inversiones en la construcción de nuevas escuelas públicas, sobre todo en pequeñas comunidades en donde no haya una cubertura de oferta educativa suficiente.

\section{Indicador: Porcentaje de abandono escolar por falta de recursos}

Según el INEGI (2013, pp. 99, 100, 145, 154), la escolaridad de los hablantes de una lengua indígena de 15 años o más, ascendió en 2010 a 5.1 años; en comparación al promedio de los mexicanos no indígenas entre 15 y 59 años, que tienen 9.3 años de asistencia a la escuela. La participación educativa de los pueblos originarios más baja está, entre otros factores, causada por su falta de recursos financieros, por ejemplo, para poder pagar las cuotas mensuales que cobran la mayoría de las escuelas públicas en México, aunque la Ley General de Educación, (Art. 6) garantiza una educación gratuita para todos. Tales costos, en combinación con cobros de matrículas, transporte, materiales escolares, uniformes y alimentación, no son accesibles para los indígenas que cuentan con niveles socioeconómicos bajos. (CLADE, 2014, p. 26) Como demuestra Schmelkes et al. (2011, p. 2), la tasa de pobreza es más elevada en comunidades indígenas que en el resto de la población, ya que en 2008 un 79.9\% de la población originaria en México recibió un ingreso menor a dos salarios mínimos mensuales. Además, la pobreza junto con otros factores, como el analfabetismo, la falta del apoyo de los padres de familia, las condiciones precarias de sus viviendas y el elevado índice de desnutrición, son las causas principales para que se tenga un acceso limitado a la educación y para los bajos índices de aprendizaje y permanencia en la escuela.

Recomendación: Prohibir por ley el cobro mensual en todas las escuelas públicas del sistema educativo mexicano y establecer un programa de apoyo económico para todos los alumnos que no puedan pagar los costos como el transporte o el uniforme, tengan la posibilidad asistir a la escuela con mayor regularidad.

\section{La aceptabilidad de la educación para los pueblos indígenas en México}

\section{Indicador: Grado de relevancia, contextualización y diversificación de los contenidos impartidos \\ $y$ de los métodos de enseñanza}

En el artículo 11 de la Ley General de Derechos Lingüísticos de los Pueblos Indígenas, se garantiza que los indígenas tendrán el derecho a una educación en su propia lengua a lo largo de su trayectoria educativa básica, la cual incluye la secundaria, pero, como anteriormente se ha destacado, la educación indígena bilingüe termina con la primaria. Después, se supone que los alumnos indígenas entrarán a una secundaria monolingüe del sistema educativo general. Por lo mismo, se puede constatar que el Estado mexicano no cumple con su obligación legal de ofrecer una educación relevante, contextualizada y diversificada a la población indígena en el nivel educativo de la secundaria.

Recomendación: Que la DGEI reciba el permiso y los recursos necesarios para poder diseñar y operar una educación secundaria indígena bilingüe en todos los contextos en donde exista esta necesidad.

Se diseñó la asignatura estatal de lengua y cultura indígena (Acuerdo 592, 2011, p. 31), que es optativa en el primer año en escuelas secundarias públicas generales ubicadas en comunidades que 
cuenten con al menos un 30\% de alumnos indígenas, esto para facilitar sus transiciones del sistema educativo indígena bilingüe al sistema general hispanohablante. La falta de una secundaria indígena bilingüe y la existencia de dicha asignatura estatal, prueba que el sistema educativo mexicano indígena y general opera bajo la lógica de que los pueblos originarios tienen que adaptarse al esquema homogeneizador, en vez de que ofrezca a ellos una educación que sea relevante para una vida en sus comunidades y por lo tanto, cultural- $y$ lingüísticamente pertinente y aceptable.

Esta lógica homogeneizadora es notable, entre otros, en los libros de texto de la DGEI (2016a), "los cuales visualizan, dignifican y valoran las diversas lenguas y culturas nacionales bajo una perspectiva de inclusión y equidad", lo cual implica que los libros están diseñados para apoyar a que los pueblos originarios estén incluidos y participen de manera equitativa en procesos educativos del sistema culturalmente dominante, en vez de que los libros estén conceptualizados por las propias comunidades con contenidos que sus integrantes consideren relevantes para los alumnos de su propio sistema educativo.

También se notan las tendencias homogeneizadoras en el marco curricular para la educación indígena primaria de la DGEI $(2015$, p. 24), en donde se "promueve la búsqueda de relaciones epistémicas entre el conocimiento de los pueblos y los aprendizajes esperados de las distintas disciplinas que componen los programas de estudio del currículo 2011". Aunque se opta por incluir conocimientos comunitarios en el plan de estudios de los alumnos indígenas, el objetivo de la educación indígena es claramente el cumplimiento de los estándares educativos definidos por los actores del sistema educativo general en lugar de estándares contextualizados y definidos por las propias comunidades indígenas de acuerdo a sus realidades.

Además, los jóvenes originarios están acostumbrados a aprender a través de la observación, exploración, imitación y experimentación que por la transmisión verbal de conocimientos. Pero, este método de enseñanza verbal está aplicado por la gran mayoría los docentes en las aulas del sistema educativo indígena, aunque esté basado en una lógica del sistema educativo general (Schmelkes et al., 2011, p. 4).

Otro aspecto homogeneizador del sistema educativo indígena, es el uso de la lengua indígena. Hay casos en los cuales se utiliza la lengua como instrumento para la alfabetización y enseñanza de los alumnos en español, lo cual limita su uso a la misma clase de alfabetización y aprendizaje de esta lengua, pero no se aplica como lengua de enseñanza en las demás materias o como lengua de enseñanza, además de que los contenidos impartidos son los del sistema educativo general y no aquellos del contexto cultural y lingüístico respectivo. Entonces, en vez de que la oferta educativa y lingüística sea adaptada a las necesidades de los alumnos indígenas, estos tienen que adaptarse a la oferta educativa existente (Schmelkes, 2007, pp. 9, 10, Narro Robles y Moctezuma Navarro, 2012, p. 171).

En resumen, por esta falta de contextualización de los programas educativos, libros de texto y contenidos en la enseñanza, por falta de una oferta coherente y adecuada del uso de las lenguas originarias en las clases escolares, así como por falta de adaptación de los métodos de enseñanza a los estilos de aprendizaje de los alumnos indígenas, perciben sus experiencias en la escuela indígena como ajenas de sus realidades.

Recomendación: Replantear el enfoque educativo del sistema indígena, de tal manera de que se permita a los actores de este sistema y de sus escuelas a poder diseñar y definir sus propios currículos, programas de estudio, contenidos de enseñanza, libros de texto, procesos de aprendizaje, métodos de enseñanza, estrategias del uso de las lenguas indígenas, sus propios estándares de calidad y sus evaluaciones, de acuerdo a los requerimientos, intereses y necesidades de las comunidades locales en donde estén ubicadas.

Además, no son las escuelas secundarias públicas generales, las que diseñan los contenidos de la asignatura estatal de lengua y cultura indígena (Acuerdo 592, 2011, p. 31) ni las que deciden 
sobre su impartición, ya que cada secretaría estatal de educación pública lo determina de acuerdo a la agenda política de su gobierno. Por ejemplo, en Chiapas, que cuenta con un $32.7 \%$ de población que se autoidentifica como indígena (INEGI, 2011, p. 85), el gobierno del partido verde optó por la asignatura estatal de educación ambiental para la sustentabilidad, en vez de la asignatura de lengua y cultura indígena (Mendoza, 2016). Este caso demuestra, que existen límites para que los docentes en las escuelas secundarias generales puedan contextualizar, interculturalizar y diversificar sus enseñanzas.

Recomendación: Permitir a las escuelas secundarias públicas generales poder diseñar sus propios programas de estudio de la asignatura estatal de lengua y cultura indígena y así, poder individualmente decidir sobre su impartición, de acuerdo a los requerimientos de sus alumnos. Eso requiere una mayor flexibilidad de la rutina laboral de los docentes del sistema educativo público mexicano.

Otro aspecto que dificulta la contextualización de la enseñanza en las escuelas indígenas, es la falta de competencias lingüísticas de parte de los docentes con las lenguas indígenas habladas en las aulas. Por un lado, solo el $63 \%$ de los docentes del sistema educativo indígena es hablante de una lengua originaria y, por otro lado, en promedio 1 de cada 5 maestros está lingüísticamente desubicado, esto significa que se encuentra en una comunidad en donde se habla otra lengua que la que el domina. Por ejemplo, en el ciclo escolar 2012-2013, la lengua que se habló en el aula no coincidió con la lengua indígena del maestro en $49 \%$ de las escuelas primarias indígenas del estado de Campeche. La SEP es responsable para la provisión de vacantes y del nombramiento oficial de los maestros indígenas, sin embargo, por razones sindicales y administrativas no puede garantizar una ubicación lingüísticamente adecuada de los docentes (Narro Robles y Moctezuma Navarro, 2012, pp. 171, 173, Schmelkes et al., 2011, p. 4, CGEIB, 2014, pp. 11, 12, Bastiani Gómez et al., 2012, p. 16)

Recomendación: Por una parte, fortalecer la formación en lenguas indígenas de los futuros docen- tes del sistema educativo indígena, para que un 100\% de ellos hablen y puedan enseñar a sus alumnos en sus lenguas y, por otra parte, establecer un sistema de ubicación lingüística, para que los docentes del sistema educativo indígena puedan aprovechar al máximo sus competencias lingüísticas, y para así poder garantizar la atención educativa lingüística de los pueblos originarios que les corresponda.

\section{Indicador: Existencia \\ de un sistema de evaluación}

Según la prueba ENLACE, PISA y otras evaluaciones educativas de acuerdo a los estándares definidos por el sistema educativo general de México y por organizaciones internacionales como la OCDE y la ONU, la calidad educativa en escuelas del sistema educativo indígena es la más baja en comparación con el sistema educativo general; fenómeno que puede ser observado en los resultados de la Evaluación del Logro referida al Sistema Educativo Nacional (ELSEN). En 2015, los alumnos del sexto grado en escuelas indígenas recibieron en matemáticas calificaciones inferiores a comparación de todos los participantes de la evaluación. Ahí, la cantidad de alumnos que obtuvieron un logro insuficiente era 3 veces mayor que en las escuelas privadas (INEE, 2015a, p. 6). Hasta la fecha no existe una prueba ENLACE u otras evaluaciones del logro escolar de los alumnos indígenas en México, que corresponda a sus contextos culturales y lingüísticos. Además, por la falta de programas educativos diseñados por las comunidades originarias, no se definen todavía estándares de una educación indígena con calidad que podrían servir como base para una evaluación contextualizada y cultural- y lingüísticamente pertinente.

Recomendación: Definir estándares de calidad educativa propios para el sistema educativo indígena por las mismas comunidades originarias y establecer un propio régimen de evaluación del logro educativo.

Desde la reforma educativa en 2013, el INEE, como institución independiente del gobierno, tiene por ley la tarea de evaluar la calidad de la educación 
en México. Por lo tanto, se creó el Sistema Nacional de Evaluación Educativa (SNEE) (INEE, 2013a). En el presente año, de inició la primera evaluación de la educación indígena, aplicando métodos cualitativos y etnográficos (Mendoza, 2016).

Recomendación: Construir en base a los datos empíricos adquiridos de manera inductiva durante la primera evaluación de la educación indígena en México por el INEE, indicadores propios que permitan poder sistematizar y contextualizar la evaluación y de esta manera poder adquirir a lo largo del tiempo una base de datos comparable.

\section{La adaptabilidad de la educación para los pueblos indígenas en México}

\section{Indicador: Existencia de programas educativos para cualquier grupo social}

Inicialmente la DGEI fue creada en 1978, con la intención de garantizar la escolarización de los pueblos originarios en sus comunidades rurales. Desde entonces incrementaron sus flujos migratorios y surgió la necesidad de otros tipos de programas de atención educativa. El gráfico 6 demuestra la variedad de programas educativos existentes implementados por la DGEI para atender a diferentes necesidades de los indígenas.

Además, existen varios tipos de servicios por parte de la Subsecretaría de Educación Básica de la SEP, que responde a requerimientos específicos de los pueblos originarios, así como de grupos migratorios y de la población rural dispersa, para así cumplir con los deberes legales señalados en el artículo 38 de la Ley General de Educación. El Consejo Nacional de Fomento Educativo (CONAFE) ofrece cursos comunitarios para la población indígena, rural y migrante, de igual manera mantiene escuelas para migrantes y telesecundarias para garantizar la participación educativa de la población en comunidades rurales de alta marginación por medios electrónicos y de comunicación, tales como la televisión, señal satelital y videos (INEE, 2016, p. 27).

Gráfico 6. Programas con una oferta educativa para atender a necesidades especificas. (DGEl / Sierra Soler, 2016, p. 3)

\begin{tabular}{|c|c|c|}
\hline $\begin{array}{l}\text { Atención educativa } \\
\text { a la población migrante }\end{array}$ & $\begin{array}{c}\text { Madres jóvenes } \\
\text { y jóvenes embarazadas }\end{array}$ & $\begin{array}{l}\text { Albergues escolares } \\
\text { indígenas }\end{array}$ \\
\hline $\begin{array}{l}\text { - parte del Programa para la Inclusión } \\
\text { y la Equidad Educativa (PIEE) } \\
\text { - } 55674 \text { servicios educativos brindados } \\
\text { - en } 29 \text { estados se brindan servicios } \\
\text { - } 47176 \text { alumnos, } 2111 \text { docentes }\end{array}$ & $\begin{array}{l}\text { - PROMAJOVEN } \\
\text { - } 16780 \text { beneficiarias } \\
\text { - entre } 12 \text { y } 18 \text { años } \\
\text { - } \text { reducción de rezago } \\
\text { educativo mediante becas }\end{array}$ & $\begin{array}{l}\text { - } \quad \text { en comunidades indígenas } \\
\text { - } \text { para indígenas y migrantes } \\
\text { - } \text { edad preescolar hasta secundaria } \\
\text { - } 1087 \text { albergues } \\
\text { - } 25 \text { centros de integración social }\end{array}$ \\
\hline
\end{tabular}

Recomendación: Ampliar esa oferta de programas educativos para lograr una asistencia escolar obligatoria hasta el nivel medio superior de todos los indígenas menores de edad como se señala en el artículo 4 de la Ley General de Educación. 
Indicador: Porcentaje de derechohabientes excluidos de la educación formal y no cubiertos por una oferta educativa alternativa

Como anteriormente se ha señalado, los indígenas abandonan la escuela más temprano que otros grupos sociales mexicanos; por ejemplo, en 2006, un promedio nacional de $20.6 \%$ de los indígenas no cuentan con ningún año de educación básica, 27.2\% de hombres y $26.5 \%$ de mujeres en hogares indígenas de 15 a 59 años, no terminaron la educación primaria (CDI, 2006, pp. 97, 99, 102). El porcentaje de la asistencia escolar de hablantes de una lengua originaria varía entre las diferentes entidades federativas, por el género y por la edad. Por ejemplo, en
San Luís Potosí 95.4\% de los hombres y 96\% de las mujeres de 5 a 14 años asistían a la escuela en 2010, sin embargo, en Colima, era el 56.5\% de los hombres y $64 \%$ de las mujeres. El promedio nacional era de $89.1 \%$ de los hombres y $88.2 \%$ de las mujeres.

Asimismo, los indígenas entran más pronto al mercado laboral a comparación de los demás. El 48.8\% de la población hablante de una lengua indígena de 12 años o más, ya es económicamente activa a comparación del $91.8 \%$ de los no indígenas entre 12 y 14 años, quienes todavía asisten a la escuela. La gráfica demuestra el porcentaje de la población de 12 años o más, hablante de una lengua indígena que es económicamente activa y que realiza quehaceres domésticos (INEGI, 2013, pp. $95,96,99,100,145,154)$.

Gráfico 7. Población hablante de lengua indígena económicamente activa y que realiza quehaceres de 12 años y más, 2010 ((INEGl, 2013, p. 100)

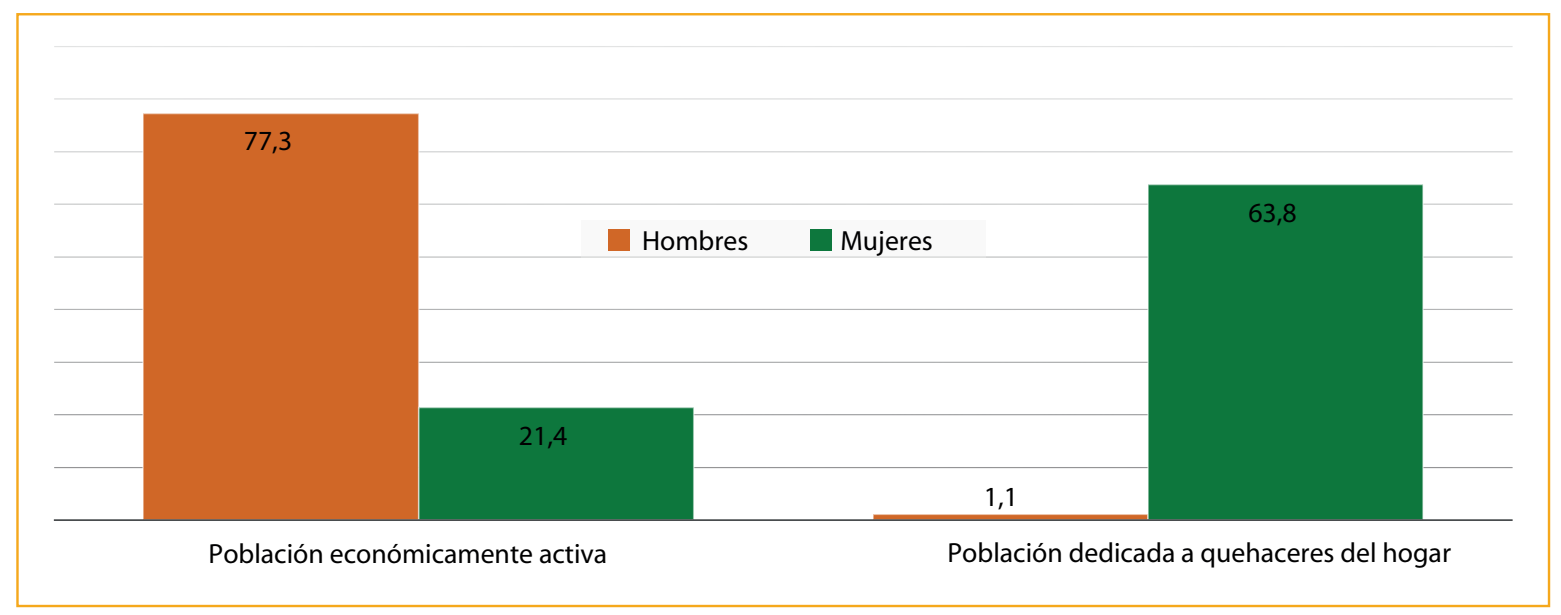

Cabe destacar que la Ley Federal de Trabajo prohíbe las actividades laborales para los menores de quince años de edad (2015, Decreto, Art. 5), pero, como señalan las estadísticas, faltan ofertas educativas alternativas que permitan a los indígenas económicamente o domésticamente activos a participar a los procesos educativos.

Recomendación: Diseñar más programas educativos alternativos que tomen en cuenta las necesidades y situaciones particulares de los indígenas y que garanticen su participación educativa.

\section{Conclusión}

El análisis de la situación educativa de los pueblos originarios en México ha demostrado que los diez criterios necesarios para una educación con calidad y equidad - basada en los criterios 4-A definidos por Tomasevski del Comité de Derechos Económicos, Sociales y Culturales (CESCR) de la Organización de las Naciones Unidas (ONU)todavía no se cumplen por completo. 
A la educación indígena le falta ser más asequible, porque este subsistema cuenta con mucho menos presupuesto por alumno en comparación con el sistema educativo general, con una infraestructura de menor estándar, así como con una cubertura y una oferta educativa más baja, los docentes reciben un sueldo inferior y tienen menos títulos académicos.

También, la educación indígena mexicana no es lo suficientemente accesible, debido a que existen procesos, estructuras y mecanismos de discriminación que excluyen a los pueblos originarios mexicanos de los procesos educativos, entre otros factores, por la falta de suficientes escuelas en localidades con pocos habitantes. En muchos casos, los indígenas no tienen otra opción que abandonar la escuela, porque sus familias o ellos mismos no pueden pagar el transporte, los materiales, el uniforme, etc.

Asimismo, la educación indígena tampoco es aceptable, ya que los contenidos y métodos de enseñanza son de baja relevancia y cuentan con poca contextualización y diversificación, por lo tanto, los alumnos indígenas perciben sus experiencias en las escuelas indígenas como ajenas de sus realidades. Aunado a ello, faltan estándares de calidad educativa basada en la visión de las comunidades indígenas, así como un sistema de evaluación que corresponda al respectivo contexto cultural y lingüístico.

La educación indígena no es suficientemente adaptable, porque los programas educativos alternativos existentes para atender todas las necesidades de los diferentes grupos sociales indígenas no logran garantizar una participación educativa de todos, por ejemplo, existe un porcentaje alto de indígenas en edad escolar que no pueden combinar sus actividades económicas o sus quehaceres domésticos con una asistencia regular a una oferta educativa.

Para asegurar la asequibilidad de la educación indígena, es recomendable redistribuir el presupuesto para la educación básica de una manera equitativa, ya que esto podría mejorar la infraestructura e intensificaría la profesionalización y la capacitación de los profesores del sistema educativo indígena. Para fortalecer la aceptabilidad, la accesibilidad y la adaptabilidad se necesitaría redefinir y interculturalizar el enfoque de la educación indígena para así poder garantizar la atención educativa de los pueblos originarios con calidad, equidad y pertinencia cultural y lingüística.

\section{Referencias bibliográficas}

Bastiani Gómez, José, Ruiz-Montoya, Lorena, Estrada Lugo, Erín, Cruz Salazar, Tania, y Aparicio Quintanilla, José (2012). Política educativa indígena. Práctica docente, castellanización, burocracia y centralización de la educación como limitaciones del éxico pedagógico en la región Ch'ol, Chiapas. Perfiles Educativos, 2012, Vol. XXXIV, núm. 135, IISUE-UNAM: http://www.scielo.org.mx/pdf/peredu/ v34n135/v34n135a2.pdf (23.03.2016).

Bertely Busquets, María (2002). Panorama histórico de la educación para los indígenas en México. UNAM, México: http://biblioweb.tic.unam.mx/diccio nario/htm/articulos/sec_5.htm (23.03.2016)

Campaña Latinoamericana por el Derecho a la Educación (CLADE) (2014). Consulta sobre la discriminación en la educación en la primera infancia. Un estudio desde la perspectiva de la comunidad educativa en escuelas de Brasil, Perú y Colombia. CLADE, Brasil: http://www.campanaderechoeducacion.org/ primerainfancia/wp-apyus/wp-content/ uploads/2014/06/CLADE_consulta_versionfinal.pdf (23.03.2016)

Cervera, Flores, Miguel (2015). Distribución de la población por tamaño de localidad y su relación con el medio ambiente. Presentación de PowerPoint para el Seminario-taller "Información para la toma de decisiones: Población y Medio Ambiente", 19.-20.02.2015, Colegio de México, México: http://www.inegi.org.mx/eventos/ 2015/Poblacion/doc/p-WalterRangel.pdf (23.03.2016).

Comisión Nacional para el Desarrollo de los Pueblos Indígenas (CDI) (2006). Indicadores con perspectiva de género para los pueblos indígenas: http://www.gob.mx/cms/uploads/attachment/file/35734/cdi-indicadores-perspectiva-genero-2006.pdf (23.03.2016). 
Consejo Nacional para Prevenir la Discriminación (CONAPRED) (2013).Discriminación en contra de la población indígena en México: http:// www.conapred.org.mx/index.php? conte nido $=$ noticias $\&$ id $=798 \&$ id_opcion $=328 \&$ $\mathrm{op}=448$ (23.03.2016).

Constitución Política de los Estados Unidos Mexicanos: Art. 2: http://info4.juridicas.unam.mx/ijure/ fed/9/3.htm?s= (23.03.2016) Art. 3: http:// info4.juridicas.unam. $\mathrm{mx} / \mathrm{ijure} / \mathrm{fed} / 9 / 4$. htm? $s=(23.03 .2016)$

Instituto Nacional de Lenguas Indígenas (INALI) (2008). Catálogo de las Lenguas Indígenas Nacionales: http://www.cdi.gob.mx/lenguamaterna/catalogo_lenguas_indigenas_mexico_2008.pdf (23.03.2016)

Instituto Nacional para la Evaluación de la Educación (INEE) (2012). Panorama Educativo de México. AR03 Gasto público por alumno total y como porcentaje del PIB per cápita (19802012): http://www.inee.edu.mx/bie/mapa indica/2012/PanoramaEducativoDeMexico/ AR/AR03/2012_AR03_c.pdf (23.03.2016). (2013). Perfil sociodemográfico, Estados Unidos Mexicanos, Censo de Población y Vivienda 2010: http://www.inegi.org.mx/ prod_serv/contenidos/espanol/bvinegi/productos/censos/poblacion/2010/perfil_socio/ uem/702825047610_1.pdf (23.03.2016).

(2013a).Sistema Nacional de EvaluaciónEducativa: http://www.inee.edu.mx/index.php/acerca-delinee/el-inee-en-la-reforma-educativa/522-reforma-educativa/sistema-nacional-de-evaluacioneducativa/1618-sistema-nacional-de-evaluacion-educativa (23.03.2016).

(2015). Los docentes en México. Informe 2015: http://publicaciones.inee.edu.mx/buscadorPub/P1/I/240/P1I240.pdf (23.03.2016)

(2015a). Resultados nacionales 2015. Matemáticas. Evaluación del Logro referida al Sistema Educativo Nacional (ELSEN): http:// publicaciones.inee.edu.mx/buscadorPub/ P2/A/318/P2A318.pdf (23.03.2016)

(2016). La educación obligatoria en México. Informe 2016: http://www.inee.edu. $\mathrm{mx} /$ images/stories/2016/informe_2016/ Informe2016-4.pdf (23.03.2016).

Lewis, M. Paul (2009). Table 1 - Distribution of living languages by country: http://www. ethnologue.com/ethno_docs/distribution. asp? by=country (23.03.2016).

Ley Federal de Trabajo de los Estados Unidos Mexicanos: http://www.diputados.gob.mx/LeyesBiblio/ pdf/125_120615.pdf (23.03.2016)

(2015). Decreto para la reforma en materia de trabajo de menores: http://www. diputados.gob.mx/LeyesBiblio/ref/lft/LFT_ ref27_12jun15.pdf (23.03.2016)

Ley General de Derechos Lingüísticos de los Pueblos Indígenas de los Estados Unidos Mexicanos (2003). http://www.diputados. gob.mx/LeyesBiblio/pdf/257_171215.pdf (23.03.2016).

Ley General de Educación de los Estados Unidos Mexicanos: http://www.diputados.gob. $\mathrm{mx} /$ LeyesBiblio/pdf/137_171215.pdf (23.03.2016).

Márquez Jiménez, Alejandro (2012). El financiamiento de la educación en México. Problemas y alternativas. En: Perfiles Educativos, XXXIV, 107117: número especial, IISUE-UNAM. http:// www.scielo.org.mx/pdf/peredu/v34nspe/ v34nspea10.pdf (23.03.2016).

Martínez Buenabad, Elizabeth (2011). La Educación indígena e intercultural en México y sus implicaciones en la construcción de ciudadanías. XI Congreso Nacional de Investigación Educativa / 12. Multiculturalismo y Educación / Ponencia: http://www.comie.org. $\mathrm{mx} /$ congreso/memoriaelectronica/v11/docs/ area_12/1004.pdf (23.03.2016)

Mejía Botero, Fernando (2012). Presupuesto federal en educación y su distribución por tipo de gasto, ramo y fondo. Impacto de la fórmula de la distribución del FAEB, 2008-2012. Revista Latinoamericana de estudios educativosvol. XLII, núm. 3, pp. 21-34. (RLEE México), http://www.cee.edu.mx/revista/r2011-20 20/r_texto/t_2012_3_02.pdf (23.03.2016).

Mendoza Zuany, Rosa Guadalupe (2016). Entrevista de experta grabada (mp3), Universidad Veracruzana, Instituto de Investigaciones en Educación, Xalapa, México. (30.05.2016).

Narro Robles, José y Moctezuma Navarro, David (2012). Hacia una reforma del Sistema Educativo Nacional. Plan de diez años para desarrollar el Sistema Educativo Nacional. UNAM, México: http://www.planeducati- 
vonacional.unam.mx/PDF/completo.pdf, http://www.planeducativonacional.unam. $\mathrm{mx} /(23.03 .2016)$.

Organización de las Naciones Unidas (ONU), Office of the High Commissioner (OHCHR)

(1948). Declaración de los derechos humanos (UDHR): http://www.un.org/en/universal-de claration-human-rights/ (23.03.2016)

(1976). Convenio Internacional sobre Derechos Económicos, Sociales y Culturales (ICESCR): http://www.ohchr.org/EN/ Professionalinterest/Pages/CESCR.aspx (23.03.2016).

(1999). Comentario General núm. 13 al art. 13 (sobre el derecho a la educación) del Convenio internacional sobre derechos económicos, sociales y culturales (ICESCR), adoptado por el Comité de Derechos Económicos, Sociales y Culturales (CESCR): http://www.ohchr.org/ EN/Issues/Education/Training/Compilation/ Pages/d)GeneralCommentNo13Therighttoe ducation(article13)(1999).aspx (23.03.2016) http://www.unescobkk.org/education/rightto-education/rights-based-approach-to-edu cation/ (23.03.2016).

(2007). Declaración de los derechos de los pueblos indígenas (UNDRIP):

http://www.ohchr.org/EN/Issues/IPeoples/Pages/ Declaration.aspx (23.03.2016).

Organización de las Naciones Unidas (ONU), Organización Internacional de Trabajo (OIT) (1989): Convenio 169 sobre pueblos indígenas y tribales: http://www.ilo.org/wcmsp5/groups/ public/@ed_norm/@normes/documents/ publication/wcms_100910.pdf (23.03.2016)

Organización para la Cooperación y el Desarrollo Económicos (OCDE) (2015). Panorama de la educación 2015, Nota País, México: https://www.oecd.org/mexico/Educationat-a-glance-2015-Mexico-in-Spanish.pdf (23.03.2016).

Schmelkes, Sylvia (2007). El impacto del programa oportunidades sobre la educación de la población indígena. Una exploración con base en estadísticas oficiales. En: X Congreso Nacional de Investigación educativa, área 12: multiculturalismo y educación: http://www.comie. org.mx/congreso/memoriaelectronica/v10/ pdf/area_tematica_12/ponencias/0444-F.pdf (23.03.2016).
(2013). Educación y pueblos indígenas: problemas de medición. INEGI, México: http:// www.inegi.org.mx/RDE/RDE_08/Doctos/ RDE_08_Art1.pdf (23.03.2016)

Schmelkes, Sylvia et al. (2011). La educación indígena en México: inconsistencias y retos. En: Observatorio ciudadano de la educación, México: http://red.pucp.edu.pe/ridei/ files/2011/08/070310.pdf (23.03.2016).

SEP (Secretaría de Educación Pública) (2013). Programa Sectorial de Educación 20132018: https://www.sep.gob.mx/work/ models/sep1/Resource/4479/4/images/PROGRAMA_SECTORIAL_DE_ EDUCACION_2013_2018_WEB.pdf (23.03.2016).

(2015). Programa para la inclusión y equidad educativa para el ejercicio fiscal 2016 (PIEE): http://dof.gob.mx/nota_detalle.php?codigo $=$ $5421440 \&$ fecha $=27 / 12 / 2015$ (23.03.2016)

SEP, Coordinación General de Educación Intercultural y Bilingüe (CGEIB) (2014). Programa Especial de Educación Intercultural 20142018 (PEEI). http://eib.sep.gob.mx/isbn/ PEEI_2014_2018.pdf (23.03.2016)

(2015)- La CGEIB-Misión, visión: http://eib. sep.gob.mx/cgeib/la-cgeib/ (23.03.2016).

SEP, Dirección General de Acreditación, Incorporación y Revalidación (2001). La Estructura del Sistema Educativo Mexicano: http://www.sep. gob.mx/work/models/sep1/Resource/1447/1/ images/sistemaedumex09_01.pdf (23.03.2016)

SEP, Dirección de la Educación Básica (DEB) (2011). Reforma Integral de la Educación Básica (RIEB), Acuerdo 592 - Articulación Educación Básica: http://www.iea.gob.mx/webiea/inf_general/ NORMATIVIDAD/7.\%20ACUERDOS/FEDE RALES/ACUERDO\%20592\%20Articulaci\% C 3\% B 3 n \% 20 Educaci \% C 3 \% B 3 n \% 20 B\%C3\%A1sica.pdf (23.03.2016).

SEP, Dirección General de Educación Indígena (DGEI) (2009). Educación básica indígena: Gestión con Resultados. http://basica. sep.gob.mx/dgei/pdf/inicio/mensajedir/ EduBasicaIndigena.pdf (23.03.2016).

(2009a). Atención educativa de calidad a la diversidad lingüística y cultural. Reforma integral de la educación básica indígena: 
http://www.uam.mx/cdi/convenios/avancesDGEI.pdf (23.03.2016).

(2015). Marco curricular de la Educación Primaria Indígena y de la población migrante: http://dgei.basica.sep.gob.mx/files/fondo_ editorial/marcos_curriculares/mc_primaria_00001.pdf (23.03.2016).

(2016). Historia de la educación indígena en México. Sierra Soler, Yesid, de la Dirección General de Educación Indígena (DGEI), Presentación de PowerPoint del 22 de abril 2016, Simposio Binacional sobre la educación de estudiantes indígenas en México y California, Ciudad de Oaxaca, México.

(2016a). La SEP cuenta con la producción editorial en lenguas indígenas más grande de América Latina: http://www.escuelasenred.com.mx/noticias-detalle.php?id=68 (23.03.2016).

SEP, Dirección General de Planeación y Estadística Educativa (2014). Principales Cifras del
Sistema Educativo Nacional 2013-2014: http:// fs.planeacion.sep.gob.mx/estadistica_e_indicadores/principales_cifras/principales_ cifras_2013_2014.pdf (23.03.2016).

Serdán Rosales, A. (2011). Panorama del gasto educativo en México 2012. Muévete por la Educación: http://www.culturadelalegalidad. org. $\mathrm{mx} /$ recursos/Contenidos/Estadsticas/ documentos/Panorama\%20del\%20gasto $\% 20$ educativo\%202012.pdf (23.03.2016).

Tapia Uribe, Medardo (2003). Estado inicial de las escuelas primarias de educación indígena del Programa Escuelas de Calidad: los indicadores de la línea de base. Revista Latinoamericana de Estudios Educativos vol. XXXIII, núm. 4, pp. 97-130: México. http://www.redalyc.org/ pdf/270/27033404.pdf (23.03.2016).

Tomasevski, Katarina (2004). Indicadores del derecho a la educación. Revista IIDH, vol. 40, 2004, pp. 341-388: http://www.corteidh.or.cr/tablas/ R08064-11.pdf (23.03.2016). 